\title{
Vitamin C Inhibits Visceral Adipocyte Hypertrophy and Lowers Blood Glucose Levels in High-Fat-Diet-Induced Obese C57BL/6J Mice
}

\author{
Younghyun Park ${ }^{\S, *}$, Joonseong Jang ${ }^{\S, *}$, Dongju Lee ${ }^{* *}$ and Michung Yoon ${ }^{\dagger, * * *}$ \\ Department of Biomedical Engineering, Mokwon University, Daejeon 35349, Korea
}

\begin{abstract}
Vitamin C (ascorbic acid) supplementation has been suggested to negatively correlate with obesity in humans and other animals. Previous studies, including ours, have demonstrated that a high-fat diet (HFD) induces obesity and related diseases such as hyperlipidemia, hyperglycemia, insulin resistance, and nonalcoholic fatty liver disease. Here, we investigated the effects of vitamin $\mathrm{C}$ on visceral adipocyte hypertrophy and glucose intolerance in $\mathrm{C} 57 \mathrm{BL} / 6 \mathrm{~J}$ mice. Mice received a low-fat diet (LFD, $10 \% \mathrm{kcal}$ fat), HFD (45\% kcal fat), or the same HFD supplemented with vitamin C (HFD-VC, $1 \%$ w/w) for 15 weeks. Visceral adiposity and glucose intolerance were examined using metabolic measurements, histology, and gene expression analyses. Mice in the HFD-VC supplementation group had reduced body weight, mesenteric fat mass, and mesenteric adipocyte size compared with HFD-fed mice. Vitamin C intake in obese mice also decreased the mRNA levels of lipogenesis-related genes (i.e., stearoyl-CoA desaturase 1 and sterol regulatory element-binding protein 1c) in mesenteric adipose tissues, inhibited hyperglycemia, and improved glucose tolerance. In addition, vitamin $\mathrm{C}$ attenuated the HFD-induced increase in the size of pancreatic islets. These results suggest that vitamin $\mathrm{C}$ suppresses HFD-induced visceral adipocyte hypertrophy and glucose intolerance in part by decreasing the visceral adipose expression of genes involved in lipogenesis.
\end{abstract}

Key Words: Ascorbic acid, Hyperglycemia, Lipogenesis, Pancreas, Visceral obesity

\section{INTRODUCTION}

Visceral obesity is strongly associated with metabolic syndrome, which includes dyslipidemia, hypertension, impaired glucose tolerance, and hepatic steatosis (Grundy, 2015). In particular, visceral adipocyte hypertrophy is a notable determinant of metabolic diseases and adipose tissue dysfunction (Haller et al., 1979; Laforest et al., 2015). Hypertrophic adipocytes produce and secrete several adipokines (e.g., tumor necrosis factor $\alpha$, leptin, and resistin) and free fatty acids, which have been implicated in the development of type 2 diabetes (T2D) and insulin resistance (Okuno et al., 1998; Jeong and Yoon, 2009; Koleva et al., 2013).

Vitamin C, also known as ascorbic acid and L-ascorbic acid, is inversely related to obesity. Plasma vitamin $\mathrm{C}$ concentrations are significantly lower in obese individuals than in lean individuals (Johnston et al., 2007; da Silva et al., 2012), and lower levels of plasma vitamin $C$ induce body weight gain and high waist circumference (Canoy et al., 2005; Johnston, 2005; Johnston et al., 2006; da Silva et al., 2012). Conversely, vitamin $C$ intake promotes weight loss

Received: October 22, 2018 / Revised: December 3, 2018 / Accepted: December 4, 2018

*Graduate student, ${ }^{* *}$ Undergraduate, ${ }^{* * *}$ Professor.

$\S$ These authors contributed equally: Younghyun Park, Joonseong Jang.

${ }^{\dagger}$ Corresponding author: Michung Yoon. Department of Biomedical Engineering, Mokwon University, Daejeon 35349, Korea.

Tel: +82-42-829-7581, Fax: +82-42-829-7590, e-mail: yoon60@mokwon.ac.kr

(C) The Korean Society for Biomedical Laboratory Sciences. All rights reserved.

(c) This is an Open Access article distributed under the terms of the Creative Commons Attribution Non-Commercial License (http://creativecommons.org/licenses/by-nc/3.0/) which permits unrestricted non-commercial use, distribution, and reproduction in any medium, provided the original work is properly cited. 
and inhibits central adiposity in overweight and obese men and women (Naylor et al., 1985; da Silva et al., 2012; GarciaDiaz et al., 2014). Similarly, vitamin C supplementation protects against obesity and adiposity in animal models of obesity, such as cafeteria diet-fed or ovariectomized rats (Campion et al., 2006; Kim et al., 2018). Vitamin C also decreases insulin glycation without affecting body weight in $o b / o b$ mice, and prevents liver steatosis in choline-deficient diet-fed rats (Abdel-Wahab et al., 2002; Oliveria et al., 2003).

High-fat diet (HFD) feeding in C57BL/6J mice induces obesity and metabolic syndrome (Winzell and Ahren, 2004; Fraulob et al., 2010). These animals are known for their demonstrable impaired glucose tolerance, insulin resistance, and insufficient compensatory islet responsiveness (Ahren and Pacini, 2002). Accordingly, this HFD-induced obese C57BL/6J mice model is used in studies of the pathophysiology of impaired glucose tolerance and T2D and in the development of new treatments (Winzell et al., 2003; Winzell and Ahren, 2004). We hypothesized that vitamin C might inhibit visceral adipocyte hypertrophy and glucose intolerance in HFD-induced obese C57BL/6J mice. To investigate this possibility, we measured the effects of vitamin $\mathrm{C}$ in $\mathrm{C} 57 \mathrm{BL}$ /6J mice fed a HFD on visceral adipose expression of genes involved in lipogenesis and, as a result, on visceral adipocyte hypertrophy and blood glucose levels.

\section{MATERIALS AND METHODS}

\section{Animal treatments}

For all experiments, eight-week-old male wild-type C57BL /6J mice ( $\mathrm{n}=8$ /group) were purchased from Central Lab Animal (Seoul, Korea) and randomly divided into three groups. The first group received a low-fat diet (LFD, 10\% kcal fat, Research Diets, Brunswick, NJ, USA). The second group received a HFD (45\% kcal fat, Research Diets). The third group received a HFD supplemented with $1 \%$ vitamin $\mathrm{C}$ (HFD-VC). All mice were fed their respective diets for 15 weeks. For the HFD-VC preparation, $10 \mathrm{~g}$ L-ascorbic acid (Sigma-Aldrich, St Louis, MO, USA) was mixed with $1 \mathrm{~kg}$ HFD. Actually mice were given a daily dose of $600 \mathrm{mg}$ of vitamin $\mathrm{C}$ per $\mathrm{kg}$ body weight, equal to $2.88 \mathrm{~g}$ of vitamin $\mathrm{C}$ for $60 \mathrm{~kg}$ body weight of human. Body weights were meas- ured daily by a person blinded to each treatment group. After an 8-h fast on the last day of the study, mice were sacrificed under diethyl ether anesthesia. Pancreas and mesenteric adipose tissues were harvested, weighed, snap-frozen in liquid nitrogen, and stored at $-80^{\circ} \mathrm{C}$. Additional sections of pancreas and mesenteric adipose tissues were prepared for histological analyses. All animal experiments were approved by the Institutional Animal Care and Use Committees of Mokwon University (permit number: NVRGS AEC-19) and were carried out in accordance with the National Research Council Guidelines.

\section{Blood analysis}

Blood glucose levels were measured using the Accu-Chek Performa System (Roche, Basel, Switzerland) Oral glucose ( $2 \mathrm{~g} / \mathrm{kg}$ body weight) tolerance tests were conducted, determining blood glucose levels at the indicated time intervals.

\section{Histological analysis}

Mesenteric adipose tissues were fixed in $10 \%$ phosphatebuffered formalin for 1 day and processed for paraffin sections. To measure adipocyte size, adipose tissue sections $(5 \mu \mathrm{m})$ were stained with hematoxylin and eosin (H\&E). To analyze pancreatic islet morphology, pancreas sections were stained with H\&E. Stained preparations were examined using an image analysis system (Media cybernetics, Bethesda, MD, USA).

\section{Quantitative real-time polymerase chain reaction (PCR)}

Total cellular RNA from mesenteric adipose tissues was prepared using Trizol reagent (Gibco-BRL, Grand Island, NY, USA) according to the manufacturer's instructions. Total cellular RNA ( $2 \mu \mathrm{g})$ was reverse transcribed using Moloney murine leukemia virus reverse transcriptase to generate an antisense cDNA template. The genes of interest were amplified from the reverse transcribed cDNA using AccuPower ${ }^{\circledR}$ GreenStar $^{\mathrm{TM}}$ qPCR PreMix (Bioneer, Deajeon, Korea) on an Excycler ${ }^{\mathrm{TM}} 96$ Real Time Quantitative Thermal Block machine (Bioneer). The PCR primers used for gene expression analyses are shown in supplemental Table 1. PCR was performed using the following conditions: denaturing at $95^{\circ} \mathrm{C}$ for $5 \mathrm{~min}$, followed by 45 cycles of $95^{\circ} \mathrm{C}$ for $10 \mathrm{~s}, 60^{\circ} \mathrm{C}$ for 
Table 1. Sequences of primers used for quantitative real-time PCR assays

\begin{tabular}{|c|c|c|}
\hline Genes & Gene bank & Primer sequences \\
\hline \multirow{2}{*}{ FAS } & \multirow{2}{*}{ NM_007988.3 } & Forward: 5'- GCCCTCCCGTACACTCACTC -3' \\
\hline & & Reverse : 5'- CTTGGGTGCTGACTACAACC -3' \\
\hline \multirow{2}{*}{$\operatorname{PPAR} \gamma$} & \multirow{2}{*}{ NM_001308354.1 } & Forward: 5'- ATTCTGGCCCACCAACTTCGG -3' \\
\hline & & Reverse : 5'- TGGAAGCCTGATGCTTTATCCCCA -3' \\
\hline \multirow{2}{*}{ SCD1 } & \multirow{2}{*}{ NM_009127.4 } & Forward: 5'- CGGAAATGAACGAGAGAAGG -3' \\
\hline & & Reverse : 5'- CCGAAGAGGCAGGTGTAGAG -3' \\
\hline \multirow{2}{*}{ SREBP-1c } & \multirow{2}{*}{ NM_001313979.1 } & Forward: 5'- CTTCTGGAGACATCGCAAAC -3' \\
\hline & & Reverse : 5'- GGTAGACAACAGCCGCATC -3' \\
\hline \multirow{2}{*}{$\beta$-actin } & \multirow{2}{*}{ NM_007393.5 } & Forward: 5'- TGGAATCCTGTGGCATCCATGAAA -3' \\
\hline & & Reverse : 5'- TAAAACGCAGCTCAGTAACAGTCCG -3' \\
\hline
\end{tabular}

A

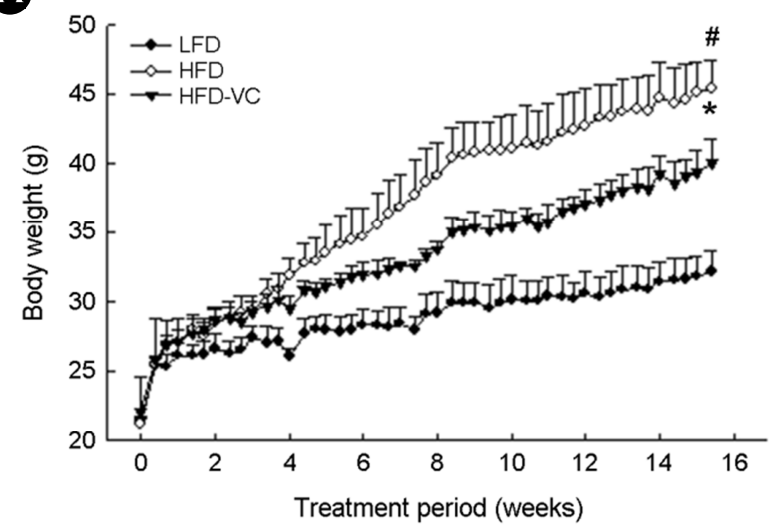

B

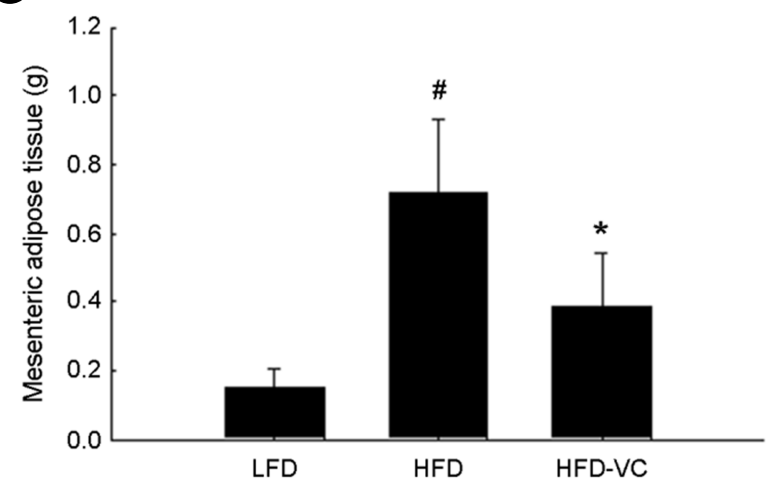

Fig. 1. Body weight and mesenteric adipose tissue mass. Adult male C57BL/6J mice were fed a low-fat diet (LFD), high-fat diet (HFD), or a HFD supplemented with vitamin C (HFD-VC) for 15 weeks. (A) Modulation of body weight by vitamin C. (B) Regulation of mesenteric fat mass by vitamin C. All values are expressed as the mean $\pm \mathrm{SD}$ ( $\mathrm{n}=8$ per group). $\# P<0.05$ compared with LFD, $* P<0.05$ compared with HFD.
$40 \mathrm{~s}$, and $72^{\circ} \mathrm{C}$ for $10 \mathrm{~s}$. Transcript concentrations were calculated as copies per $\mu \mathrm{L}$ using a standard curve, and the relative expression levels were calculated as the ratio of target gene cDNA to $\beta$-actin cDNA.

\section{Statistical analysis}

All values are expressed as mean \pm standard deviation (SD). Groups were compared by analysis of variance, followed by Tukey's multiple comparison test; $P<0.05$ was considered significant.

\section{RESULTS}

\section{Regulation of body weight and mesenteric adipose tissue} mass by vitamin $\mathrm{C}$

To determine whether vitamin $\mathrm{C}$ regulates visceral obesity in nutritionally obese mice, we measured body weight and visceral mesenteric adipose tissue mass in C57BL/6J mice fed a LFD, a HFD, or a HFD-VC for 15 weeks. After 15 weeks of treatment, HFD mice showed a $40 \%$ greater body weight than did LFD mice (Fig. 1A). In contrast, HFD-VC mice had a $13 \%$ lower body weight than did HFD mice. Mesenteric adipose tissue mass was decreased significantly by vitamin $\mathrm{C}$ supplementation in HFD mice. As shown in Fig. 1B, the mass of mesenteric fat pads in the HFD-VC mice was reduced by $46 \%$ compared with that of HFD mice. 
A

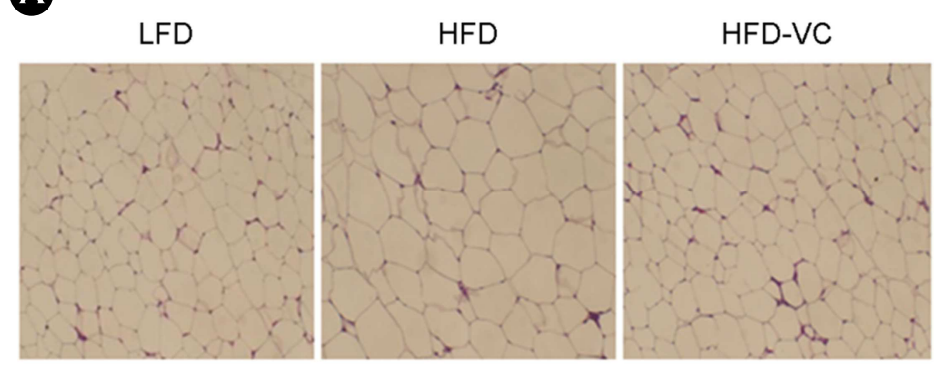

B

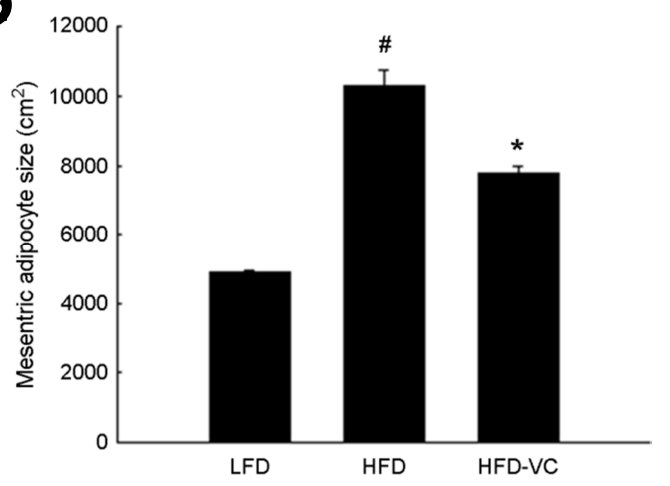

Fig. 2. Histology of mesenteric adipose tissues. Adult male C57BL/6J mice were fed a low-fat diet (LFD), high-fat diet (HFD), or a HFD supplemented with vitamin C (HFD-VC) for 15 weeks. (A) Histological analysis of visceral adipose tissue. Representative H\&E-stained visceral adipose tissue sections (original magnification $\times 100$ ). (B) Analysis of visceral adipocyte size. The size of adipocytes in a fixed area $\left(1,000,000 \mu \mathrm{m}^{2}\right)$ was measured. All values are expressed as the mean $\pm \mathrm{SD}(\mathrm{n}=8$ per group). $\# P<0.05$ compared with $\mathrm{LFD}, * P<0.05$ compared with HFD.

\section{Modulation of visceral adipocyte size by vitamin C}

Consistent with the attenuation of HFD-induced body and visceral fat weight gain, vitamin $\mathrm{C}$ supplementation significantly decreased the adipocyte size as determined by H\&Estained mesenteric adipose tissue sections (Fig. 2A). The average size of mesenteric adipocytes in HFD-VC mice $\left(5506 \pm 503 \mu \mathrm{m}^{2}\right)$ was significantly decreased by $37 \%$ compared with that of HFD mice $\left(8372 \pm 492 \mu \mathrm{m}^{2}\right.$; Fig. $\left.2 \mathrm{~B}\right)$.

\section{Modulation of lipogenesis-related gene expression by vitamin $\mathbf{C}$}

To determine whether the decreases in mesenteric fat weight and adipocyte size induced by vitamin $\mathrm{C}$ treatment resulted from inhibition of lipogenesis, we examined the effects of vitamin $\mathrm{C}$ on the expression of lipogenic enzymes and their regulators, including fatty acid synthase (FAS), stearoyl-CoA desaturase 1 (SCD1), sterol regulatory elementbinding protein 1c (SREBP-1c), and peroxisome proliferatoractivated receptor $\gamma(\mathrm{PPAR} \gamma)$. Levels of SCD1 and SREBP1c mRNA were significantly decreased by $36 \%$ and $15 \%$, respectively, in HFD-VC mice compared with those in HFD mice (Fig. 3).

\section{Regulation of blood glucose levels by vitamin C}

To determine the effects of vitamin $\mathrm{C}$ on glucose metabolism, we measured fasting blood glucose concentrations

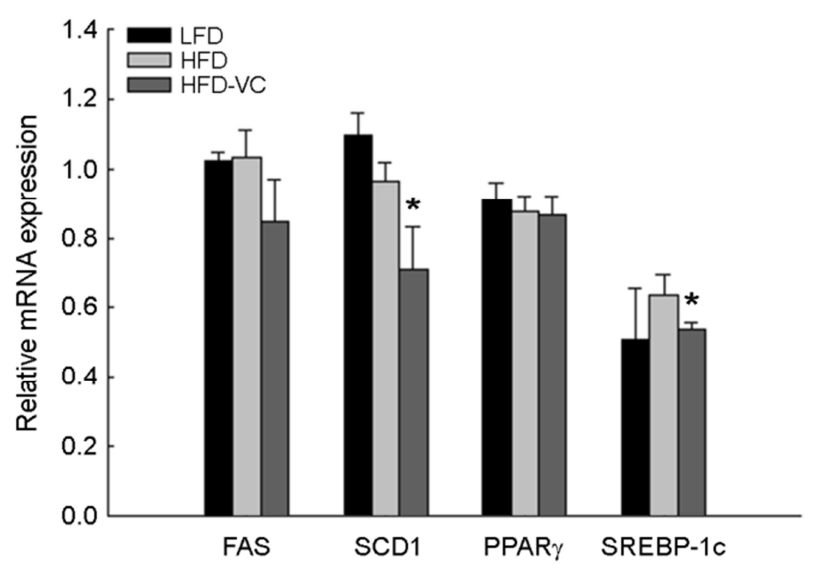

Fig. 3. Visceral adipose expression of genes involved in lipogenesis. Adult male C57BL/6J mice were fed a low-fat diet (LFD), high-fat diet (HFD), or a HFD supplemented with vitamin C (HFDVC) for 15 weeks. All values are expressed as mean \pm SD ( $n=8$ per group). $* P<0.05$ compared with HFD.

in LFD, HFD, and HFD-VC mice groups. HFD mice had $59 \%$ higher blood glucose levels than those of LFD mice (Fig. 4A), and vitamin $\mathrm{C}$ treatment reduced these higher concentrations by $36 \%$. Similarly, HFD-VC mice had significantly improved glucose tolerance compared to HFD-fed obese mice. Vitamin C-treated mice exhibited significant reductions in blood glucose levels $30 \mathrm{~min}$ after oral glucose administration compared with untreated HFD mice (Fig. 4B). 


\section{Regulation of pancreatic islet hypertrophy by vitamin C}

Because vitamin $\mathrm{C}$ treatment improved glucose tolerance, we assessed the effects of vitamin $\mathrm{C}$ on pancreatic islet morphology by evaluating H\&E-stained pancreatic tissue sections. As shown in Fig. 5, pancreatic islets in HFD mice were significantly larger than those in LFD mice. However, vitamin C supplementation to HFD mice inhibited islet hypertrophy, reducing the islet size to the level seen in LFD mice.

\section{DISCUSSION}

Vitamin C, a water-soluble vitamin found in foods and used as a dietary supplement, has antioxidant and tissue repair functions, and acts as a cofactor for the enzymatic synthesis of neurotransmitters, collagen, and carnitine. High levels of vitamin $\mathrm{C}$ intake are suggested to negatively correlate with obesity in humans and animals, as well as the development of scurvy, cancers, and cardiovascular diseases (Campion et al., 2006; Johnston et al., 2007; Garcia-Diaz et al., 2014). Because our previous study demonstrated that vitamin $\mathrm{C}$ regulates obesity and nonalcoholic fatty liver disease in HFD-fed C57BL/6J mice (in press), we hypothesized that vitamin $\mathrm{C}$ may regulate visceral adipocyte hypertrophy and impaired glucose tolerance during obesity.

In this study, treatment of HFD-induced obese C57BL/6J mice with large quantities of vitamin $\mathrm{C}$ for 15 weeks demonstrated that vitamin $\mathrm{C}$ significantly decreased body weight,
A

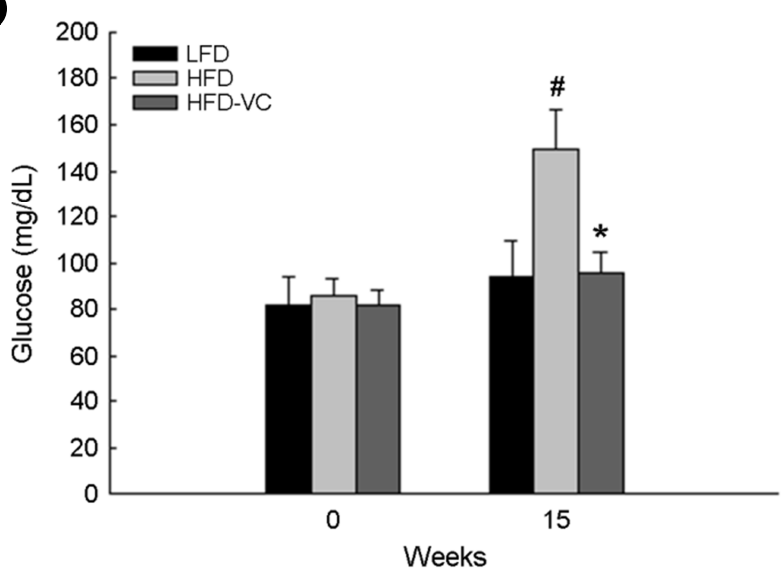

B

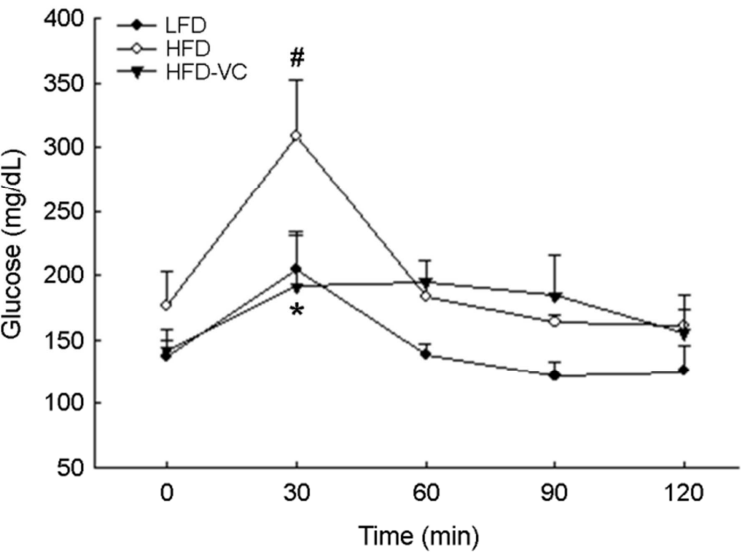

Fig. 4. Blood glucose levels and oral glucose tolerance test. Adult male C57BL/6J mice were fed a low-fat diet (LFD), high-fat diet (HFD), or a HFD supplemented with vitamin C (HFD-VC) for 15 weeks. (A) Fasting glucose and (B) oral glucose tolerance test. All values are expressed as mean $\pm \mathrm{SD}$ ( $\mathrm{n}=8$ per group). $\# P<0.05$ compared with $\mathrm{LFD}, * P<0.05$ compared with HFD.
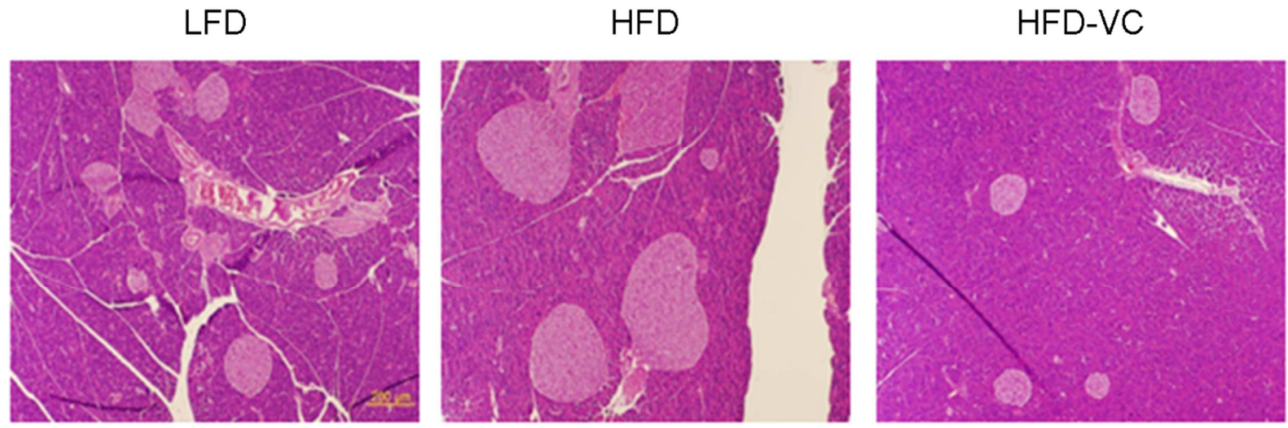

Fig. 5. Histology of pancreatic islets. Adult male C57BL/6J mice were fed a low-fat diet (LFD), high-fat diet (HFD), or a HFD supplemented with vitamin $\mathrm{C}(\mathrm{HFD}-\mathrm{VC})$ for 15 weeks. Representative H\&E-stained pancreatic tissue sections (original magnification $\times 40$ ). 
visceral mesenteric fat mass, and mesenteric adipocyte size in part through the decreased expression of lipogenic enzymes and their regulators in mesenteric adipose tissues. In addition, vitamin $\mathrm{C}$ lowered fasting glucose levels and improved oral glucose tolerance due, in part, to the decreased size of visceral adipocytes.

Mice, unlike humans, can endogenously synthesize vita$\min \mathrm{C}$ and seem to be only slightly influenced by exogenous vitamin C (Grollman and Lehninger, 1957; Chatterjee et al., 1975). However, administration of large quantities of vitamin $\mathrm{C}$ increases circulating vitamin $\mathrm{C}$ concentrations to high levels. Treatment with large amounts of vitamin $\mathrm{C}$ decreased weight gain significantly in HFD-fed mice, which parallels other reports showing that vitamin $\mathrm{C}$ supplementation results in weight loss in humans (Naylor et al., 1985; da Silva et al., 2012; Johnston, 2005) and animals (Campion et al., 2006; Kim et al., 2018). Survey data also suggest that vitamin C is inversely associated with body weight, adiposity, and waistto-hip measurement ratio (Kant, 2003; Canoy et al., 2005; Johnston et al., 2006; da Silva et al., 2012).

Consistent with the effects of vitamin $\mathrm{C}$ on mesenteric adipose tissue mass, histological examination of mesenteric adipose tissue sections revealed that vitamin $\mathrm{C}$ supplementation significantly decreased the average size of adipocytes in HFD-induced obese mice, indicating that vitamin $\mathrm{C}$ may stimulate the conversion of large adipocytes into smaller adipocytes. Hypertrophic adipocytes increase circulating levels of fatty acids and inflammatory cytokines, leading to glucose intolerance, insulin resistance, nonalcoholic fatty liver disease, and cardiovascular disease (Després and Lemieux, 2006; Jeong and Yoon, 2009; Kim et al., 2017). Based on these results showing that vitamin $\mathrm{C}$ inhibited visceral adipocyte hypertrophy, vitamin $\mathrm{C}$ may serve as a promising therapeutic approach for the treatment of visceral obesity and related metabolic diseases.

Excess lipid accumulation in adipose tissues is promoted by a number of transcription factors, including PPAR $\gamma$, SREBP-1c, and members of the CCAAT/enhancer-binding protein family (Ntambi et al., 2000; Rosen and MacDougald, 2006; Tang and Lane, 2012). These master regulators of adipogenesis and lipogenesis function by inducing transcription of targets such as SCD1, FAS, and acetyl-CoA carboxy- lase (Rosen and MacDougald, 2006; Strable and Ntambi, 2010). Armed with this knowledge of how excess lipid accumulation is induced in adipose tissue, we next examined whether the decreases in visceral adipose tissue mass and adipocyte size induced by vitamin $\mathrm{C}$ treatment may be caused by inhibitory effects of vitamin $\mathrm{C}$ on the adipose expression of lipogenesis-related genes. We observed that vitamin $\mathrm{C}$ supplementation decreased mRNA levels of SCD1 and SREBP-1c in adipose tissues of HFD mice. These results suggest that vitamin $\mathrm{C}$ may decrease visceral obesity and adipocyte hypertrophy in part by reducing adipose expression of genes involved in lipogenesis.

Furthermore, we showed that chronic intake of a HFD increased fasting blood glucose levels, but that vitamin $\mathrm{C}$ treatment significantly reduced glucose concentrations in HFD obese mice. In parallel with its glucose-lowering abilities, vitamin $\mathrm{C}$ reduced blood glucose levels during oral glucose tolerance tests, suggesting that vitamin $\mathrm{C}$ may alleviate impaired glucose tolerance of obese mice. Consistent with our results, vitamin $\mathrm{C}$ supplementation has been shown to decrease blood glucose levels in ob/ob mice and cafeteria diet-fed rats, as well as patients with T2D (Abdel-Wahab et al., 2002; Garcia-Diaz et al., 2014; Ashor et al., 2017). Moreover, Williams et al. (2016) reported that dietary supplementation with vitamins $\mathrm{E}$ and $\mathrm{C}$ attenuates dexamethasoneinduced glucose intolerance in rats. Taken together, these results indicate that vitamin $\mathrm{C}$ supplementation repressed hyperglycemia and glucose intolerance during 15 weeks of HFD intake.

It is well known that insulin resistance in obesity is associated with expansion of islet $\beta$-cell mass, as shown in genetic and diet-induced models of obesity (Winzell and Ahrén, 2004; Ahrén et al., 2010). Given endocrine cells of pancreatic islets play important roles in glucose metabolism, we examined H\&E-stained pancreatic sections in LFD, HFD, and HFD-VC mouse groups. The examination revealed that pancreatic islet size was markedly higher in HFD mice than in LFD mice and decreased in HFD-VC mice to a size similar to those in LFD mice.

In conclusion, we have shown that vitamin $\mathrm{C}$ inhibits visceral adipocyte hypertrophy and glucose intolerance by regulating visceral adipose expression of genes involved in 
lipogenesis in HFD-fed obese mice. These findings suggest that vitamin $\mathrm{C}$ may be a promising therapeutic approach for preventing and treating visceral obesity and glucose intolerance.

\section{ACKNOWLEDGEMENT}

This work supported by the National Research Foundation of Korea (NRF) Grant funded by the Korea Government (MEST) (2015R1A1A3A04001016).

\section{CONFLICT OF INTEREST}

The authors report no conflicts of interest.

\section{REFERENCES}

Abdel-Wahab YH, O'Harte FP, Mooney MH, Barnett CR, Flatt PR. Vitamin $\mathrm{C}$ supplementation decreases insulin glycation and improves glucose homeostasis in obese hyperglycemic (ob/ob) mice. Metabolism. 2002. 51: 514-517.

Ahrén J, Ahrén B, Wierup N. Increased $\beta$-cell volume in mice fed a high-fat diet: a dynamic study over 12 months. Islets. 2010. 2: 353-356

Ahrén B, Pacini G. Insufficient islet compensation to insulin resistance vs. reduced glucose effectiveness in glucose-intolerant mice. American Journal of Physiology. Endocrinology and Metabolism. 2002. 283: E738-E744.

Ashor AW, Werner AD, Lara J, Willis ND, Mathers JC, Siervo M. Effects of vitamin C supplementation on glycaemic control: a systematic review and meta-analysis of randomised controlled trials. European Journal of Clinical Nutrition. 2017. 71: 1371 -1380 .

Campión J, Milagro FI, Fernández D, Martínez JA. Diferential gene expression and adiposity reduction induced by ascorbic acid supplementation in a cafeteria model of obesity. Journal of Physiology and Biochemistry. 2006. 62: 71-80.

Canoy D, Wareham N, Welch A, Bingham S, Luben R, Day N, Khaw KT. Plasma ascorbic acid concentrations and fat distribution in 19,068 British men and women in the European Prospective Investigation into Cancer and Nutrition Norfolk cohort study. The American Journal of Clinical Nutrition. 2005. 82: 1203-1209.

Chatterjee IB, Majumder AK, Nandi BK, Subramanian N. Synthesis and some major functions of vitamin $\mathrm{C}$ in animals. Annals of the New York Academy of Sciences. 1975. 258: 24-47. da Silva VR, Moreira EA, Wilhelm-Filho D, de Miranda JX, Benincá JP, Vigil SV, Moratelli AM, Garlet TR, de Souza Meirelles MS, Vannucchi H, Fröde TS. Proinflammatory and oxidative stress markers in patients submitted to Roux-en-Y gastric bypass after 1 year of follow-up. European Journal of Clinical Nutrition. 2012. 66: 891-899.

Després JP, Lemieux I. Abdominal obesity and metabolic syndrome. Nature. 2006. 444: 881-887.

Fraulob JC, Ogg-Diamantino R, Fernandes-Santos C, Aguila MB, Mandarim-de-Lacerda CA. A Mouse Model of Metabolic Syndrome: Insulin Resistance, Fatty Liver and Non-Alcoholic Fatty Pancreas Disease (NAFPD) in C57BL/6 Mice Fed a High Fat Diet. Journal of Clinical Biochemistry and Nutrition. 2010. 46: 212-223.

Garcia-Diaz DF, Lopez-Legarrea P, Quintero P, Martinez JA. Vita$\min C$ in the treatment and/or prevention of obesity. Journal of Nutritional Science and Vitaminology. 2014. 60: 367-379.

Grollman AP, Lehninger AL. Enzymic synthesis of L-ascorbic acid in different animal species. Archives of Biochemistry and Biophysics. 1957. 69: 458-467.

Grundy SM. Adipose tissue and metabolic syndrome: too much, too little or neither. European Journal of Clinical Investigation. 2015. 45: 1209-1227.

Haller H, Leonhardt W, Hanefeld M, Julius U. Relationship between adipocyte hypertrophy and metabolic disturbances. Endokrinologie. 1979. 74: 63-72.

Jeong S, Yoon M. Fenofibrate inhibits adipocyte hypertrophy and insulin resistance by activating adipose PPAR $\alpha$ in high fat dietinduced obese mice. Experimental \& Molecular Medicine. 2009. 41: 397-405.

Johnston CS. Strategies for healthy weight loss: from vitamin C to the glycemic response. Journal of the American College of Nutrition. 2005. 24: 158-165.

Johnston CS, Beezhold BL, Mostow B, Swan PD. Plasma vitamin $\mathrm{C}$ is inversely related to body mass index and waist circumference but not to plasma adiponectin in nonsmoking adults. The Journal of Nutrition. 2007. 137: 1757-1762.

Johnston CS, Corte C, Swan PD. Marginal vitamin C status is associated with reduced fat oxidation during submaximal exercise in young adults. Nutrition \& Metabolism. 2006. 3: 35.

Kant AK. Interaction of body mass index and attempt to lose weight in a national sample of US adults: association with reported food and nutrient intake, and biomarkers. European Journal of Clinical Nutrition. 2003. 57: 249-259.

Koleva DI, Orbetzova MM, Atanassova PK. Adipose tissue hor- 
mones and appetite and body weight regulators in insulin resistance. Folia Medica. 2013. 55: 25-32.

Kim B, Choi KM, Yim HS, Park HT, Yim JH, Lee MG. Adipogenic and lipolytic effects of ascorbic acid in ovariectomized rats. Yonsei Medical Journal. 2018. 59: 85-91.

Kim J, Lee H, Lim J, Oh J, Shin SS, Yoon M. The angiogenesis inhibitor ALS-L1023 from lemon-balm leaves attenuates highfat diet-induced nonalcoholic fatty liver disease through regulating the visceral adipose-tissue function. International Journal of Molecular Sciences. 2017. 18: E846.

Laforest S, Labrecque J, Michaud A, Cianflone K, Tchernof A. Adipocyte size as a determinant of metabolic disease and adipose tissue dysfunction. Critical Reviews in Clinical Laboratory Sciences. 2015. 52: 301-313.

Naylor GJ, Grant L, Smith C. A double blind placebo controlled trial of ascorbic acid in obesity. Nutrition and Health. 1985. 4: 25-28.

Ntambi JM, Young-Cheul K. Adipocyte differentiation and gene expression. The Journal of Nutrition. 2000. 130: 3122S-3126S.

Oliveira CP, Gayotto LC, Tatai C, Della Nina BI, Lima ES, Abdalla DS, Lopasso FP, Laurindo FR, Carrilho FJ. Vitamin C and vitamin $\mathrm{E}$ in prevention of nonalcoholic fatty liver disease (NAFLD) in choline deficient diet fed rats. Nutrition Journal. 2003. 2: 9 .

Okuno A, Tamemoto H, Tobe K, Ueki K, Mori Y, Iwamoto K, Umesono K, Akanuma Y, Fujiwara T, Horikoshi H, Yazaki Y, Kadowaki T. Troglitazone increases the number of small adipocytes without the change of white adipose tissue mass in obese Zucker rats. The Journal of Clinical Investigation. 1998.
101: 1354-1361.

Rosen ED, MacDougald OA. Adipocyte differentiation from the inside out. Nature Reviews. Molecular Cell Biology. 2006. 7: 885-896.

Strable MS, Ntambi JM. Genetic control of de novo lipogenesis: role in diet-induced obesity. Critical Reviews in Biochemistry and Molecular Biology. 2010. 45: 199-214.

Tang QQ, Lane MD. Adipogenesis: from stem cell to adipocyte. Annual Review of Biochemistry. 2012. 81: 715-736.

Williams DB, Wan Z, Frier BC, Bell RC, Field CJ, Wright DC. Dietary supplementation with vitamin $\mathrm{E}$ and $\mathrm{C}$ attenuates dexamethasone-induced glucose intolerance in rats. American journal of physiology. Regulatory, Integrative and Comparative Physiology. 2012. J302: R49-R58.

Winzell MS, Ahrén B. The high-fat diet-fed mouse: a model for studying mechanisms and treatment of impaired glucose tolerance and type 2 diabetes. Diabetes. 2004. 53: S215-S219.

Winzell MS, Holm C, Ahrén B. Downregulation of islet hormonesensitive lipase during long-term high-fat feeding. Biochemical and Biophysical Research Communications. 2003. 304: 273 -278 .

https://doi.org/10.15616/BSL.2018.24.4.311

Cite this article as: Park Y, Jang J, Lee D, Yoon M. Vitamin C Inhibits Visceral Adipocyte Hypertrophy and Lowers Blood Glucose Levels in High-Fat-Diet-Induced Obese C57BL/6J Mice. Biomedical Science Letters. 2018. 24: 311-318. 